\title{
Transgender community and the increased risk of suicide
}

\begin{abstract}
Transgender is an over-arching term and is often categorized by a person's gender at birth and what gender they now identify as. It is important to understand that there is a great deal of diversity within the transgender community with people who are transgender engaging in sex with same sex and those of the opposite sex. While progress has been made in advocating for civil rights for transgender people, historically transgender people have been the victims of societal discrimination and marginalization because they have not remained in their assigned gender role. Prevalence of suicide attempts among the transgender population is $41 \%$; grossly exceeding the overall U.S. population of $4.6 \%$. Interventions addressing multiple public health problems within this community could have a positive impact over time. More attention need to be paid to this population and more resources allocated to develop and implement intervention programs, specifically focusing on substance abuse, poor mental health, violence and victimization, discrimination, and economic hardship.
\end{abstract}

Keywords: transgender, transgender and suicide, gender identity, MTF, FTM, suicide
Volume 4 Issue 4 - 2016

\author{
Daryl Johnson \\ Department of Health and Mental Hygiene, USA
}

Correspondence: Daryl Johnson, Department of Health and Mental Hygiene, 42-09 28th Street, Long Island City, USA, Tel 6195499709, Email darylec@gmail.com

Received: April 14, 2016 | Published: May 05, 2016
Abbreviations: MTF, male to female; FTM, female to male; NTDS, national transgender discrimination survey; CDC, centers for disease control and prevention

\section{Introduction}

Transgender is an overarching term used to describe people who "... have gender identities, expressions, or behaviors not traditionally associated with their birth sex". ${ }^{1}$ Transgender people are often categorized by their gender at birth and what gender they now identify as (e.g., male-to-female (MTF) and female-to-male (FTM)). However, it is important to note that assumptions should not be made about a person's sexual orientation and sexual behavior solely based on gender identity. For example, it is common for transgender men to state they have a variety of sexual orientations. Furthermore, they may engage in sex with gay men as well as transgender women. ${ }^{2}$

While society has traditionally grouped transgender people into different categories, it is important to understand that there is still a great deal of diversity within the transgender community. It might be of interest to know that certain transgender people identify as male or female, male and female, or as neither male nor female. As one trans activist wrote, "gender-identity is the manner in which we think of ourselves, our internal conviction about being men or women, male or female, masculine or feminine, and both or neither". ${ }^{3}$

Historically, transgender people have been the victims of societal discrimination and marginalization because they have not remained in their assigned gender role (i.e., gender at birth) or are gender-nonconforming. ${ }^{4}$ Since the early 1990 's, the transgender movement has made good strides in advocating for civil rights for transgender people and looking for ways to improve the overall health and welfare of the transgender community. Additionally, researchers began documenting a variety of key issues that were, and still are, relevant to the transgender community (e.g., adverse social and health consequences of discrimination and oppression).

One key health problem that stands out for this community is the suicide rate. ${ }^{1}$ The results of a 2008 National Transgender Discrimination Survey (NTDS), conducted by the National Gay and Lesbian Task Force and National Center for Transgender Equality and released in January 2014, states that the prevalence of suicide attempts among the transgender population who report a suicide attempt within their lifetime is $41 \%$.This grossly exceeds the overall U.S. population of $4.6 \%$. Fifty percent of those reporting a suicide attempt within their life time disclosed that they were transgender or gender-non-conforming to everyone in their network. NTDS goes on to report that transgender survey respondents, who were the target of discrimination, victimization, violence, or rejection by family and friends, have a higher risk of attempting suicide than other populations. Some sources suggest up to four times the risk. ${ }^{5}$ Of those surveyed, $78 \%$ reported they had attempted suicide as a result of physical or sexual violence at school, with $65 \%$ having experienced violence at work. ${ }^{6}$

Interventions addressing multiple public health problems within this community could have a positive impact over time. Examples of intervention programs, specifically focusing on this population could include: substance abuse, poor mental health, violence and victimization, discrimination, and economic hardship. A multidisciplinary (i.e., social services, mental health, primary care doctor, etc.) approach potentially could prove useful in improving health outcomes for this population. ${ }^{2}$

\section{Conclusion}

The numbers related to suicide attempts vary slightly depending on which study you read on the transgender community. Additionally, it is nearly impossible to know the exact number of successful suicides within the transgender community. This is due to the fact that sexual orientation is not listed on a death certificate. One fact that is crystal clear is that transgender people have a much higher likelihood of attempting suicide than any other sub-population, especially among the youth and young adults. According to the Centers for Disease Control and Prevention (CDC) in 2011, ${ }^{7}$ suicide is the 2nd leading cause of death among all young people ages 10 to 24 . Sexual 
minority status is a key risk factor for suicide among lesbian, gay, and bisexual youth. Could this explain why the suicide numbers are so high among the youth? Whatever the reason, more attention needs to be paid to mental health issues, especially among the more vulnerable populations including people who are transgender. ${ }^{8,9}$

\section{Acknowledgements}

Alejandro Varela, MPH, Adjunct Professor, Long Island University, Brooklyn Campus

Thomas J. Johnson, MS, RRT; Associate Professor, Long Island University, Brooklyn Campus.

\section{Conflict of interest}

The author declares no conflict of interest.

\section{References}

1. Kenagy GP. Transgender health: Findings from two needs assessment studies in Philadelphia. Health Soc Work. 2005;30(1):19-26.
2. CDC. HIV among Transgender People. USA: Centers for Disease Control and Prevention; 2013.

3. Singer B. Trans identities: Language has the power to erase or selfdefine. 1997.

4. MacKenzie GO. Transgender nation. USA: Bowling Green State University Popular Press; 1994.

5. Facts about Suicide.

6. Herman JL, Haas AP, Rodgers PL. Suicide Attempts among Transgender and Gender Non-Conforming Adults. USA: The Williams Institute; 2014.

7. CDC. Ten Leading Causes of Death and Injury. USA: Centers for Disease Control and Prevention; 2014.

8. Grossman AH, D'Augelli AR. Transgender Youth and Life-Threatening Behaviors. Suicide Life Threat Behav. 2007;37(5):527-537.

9. Dean Spade. Impossibility Now, a video and slideshow. BCRW; 2013. 